\title{
Meio Diva, meio Geni: Butler entre nós ${ }^{1}$
}

Karla Bessa²

- título da minha fala de hoje - "Meio diva, meio Geni: Butler entre nós" - ecoa o sucesso que Butler fez em sua primeira visita ao Brasil, em 2015, quando foi recebida como uma diva queer, por uma audiência de leitores oriundos de diferentes campos do conhecimento e outros que a leram como inspiração para sua própria vida ou ativismo. Geni, como uma clara referência à personagem travesti marginalizada da letra/música de Chico Buarque, ${ }^{3}$ pois Butler sofreu um apedrejamento simbólico, além de atentados físicos contra sua pessoa, ${ }^{4}$ por parte de uma direita (herdeira do conservadorismo e dispositivos autoritários da Ditadura) raivosa que viu na autora a representação de uma figura devassa, que propaga ideias perigosas e corruptoras da juventude, a partir de sua noção performativa do gênero e da sexualidade. Essa imagem ambígua de Butler, meio diva, meio Geni, pareceu-me ser um bom início para nossa conversa. Hoje, quando celebramos os 30 anos de Gender Trouble (Problemas de Gênero) poderíamos estar distantes do contexto político que o motivou, ou seja, a presença de dispositivos relacionais e institucionais que regulam as dinâmicas de gênero e sexualidade a partir de uma heterossexualidade compulsória e do binarismo do gênero que demarcam, a partir dos mais diferentes modos de violência e anulação das diferenças, de modo global e colonialista as instituições e práticas que normatizam/regulam nossos corpos e vidas.

\footnotetext{
1 Texto decorrente de fala ministrada no dia quatro de dezembro de 2020. Esta comunicação e o debate realizado por Priscila Vieira (DEHIS-UFPR) podem ser acessados na íntegra através do canal do Programa de Pós-Graduação em Sociologia da UFPR no Youtube. Disponível em: $<$ https://www.youtube.com/watch?v=HSceqAkSWyM\&t=388s>. Acesso em 17 de abril de 2021.

2 Pesquisadora Nivel C no Núcleo de Estudos de Gênero Pagu, é professora plena dos Programas de Pósgraduação em Multimeios, Instituto de Artes e do Programa de Pós-graduação em Ciências Sociais, na Universidade Estadual de Campinas (Unicamp).

3 BUARQUE, Chico. Geni e o Zeppelin. In: Opera do Malandro, 1978 (album musical) há ainda a peça teatral homônima, tambem escrita em 1978.

4 Dentre as várias reportagens sobre os atentados (de 2015 e de 2017), deixo aqui uma que sintetiza bem as forças que se contrapuseram na recepçāo de Butler no Brasil: Não é o fim da história', diz filósofa sobre ensino de gênero nas escolas. Disponível em <http://g1.globo.com/educacao/noticia/2015/og/nao-e-ofim-da-historia-diz-filosofa-sobre-ensino-de-genero-nas-escolas.html>. Acesso em 10 de Maio de 2021.
} 
Idealmente, eu desejaria que estivéssemos numa outra configuração, na qual o que os discursos disciplinantes e coercitivos denominam de dissidência e/ou transgressão em relação à sexualidade e gênero fossem apenas uma variação histórica e plural dentro de entendimento de que somos muitos e variados seres vivos existentes, que nos reconhecemos como diferentes, porem equivalentes no que toca à cidadania, aos direitos humanos, civis e políticos. Mais do que uma equidade formal (que garanta relações respeitosas), o meu desejo era de que a gente pudesse hoje celebrar a acolhida de corpos, desejos, subjetividades que expressam territorialidades já conhecidas e outras ainda por-vir; ou seja, que tivéssemos finalmente compreendido aquilo que o texto de Butler tanto nos convoca, ou seja, que haverá sempre uma diferença a nos fazer suspeitar das nossas racionalidades e convenções do que seja humano, sexual, homem, mulher, corpo e matéria, e estivéssemos abertos para os arranjos que se pode fazer no plano do desejo, do prazer, do erotismo, para além das restrições religiosas, jurídicas, familiares e ou discriminações cientificas baseadas em supostos universais, como se houvesse uma fatalidade a nos impingir o significado da vida. Não que os corpos e subjetividades não escapem das normas, mas é que ao se colocarem no modo dissonante/dissidente, enfrentam a fúria social do desrespeito, da precarização de suas existências.

As reflexões de Gender trouble nos instigam a exercermos nossa imaginação político-utópica de uma vida social não violenta e que não subjuga as diferenças para transformá-las em princípios de semelhanças e identidades reconhecidas como únicas e portadoras de uma verdade inquestionável. O problema de gênero não é o caráter performativo do gênero, mas o modo violento como dinâmicas e estruturas sociais tentam dizimar qualquer alteridade que emerja na processualidade na qual engendramos nossos corpos-subjetividades no espaço/tempo social, desestabilizando relações e formas já instituídas de nos reconhecermos enquanto sujeitos e indivíduos dignos de existência plena. Os corpos e desejos em desacordo com constrições e normas possuem essa capacidade de desnaturalizar nossa percepção não só do “outro”, mas da vida em si mesma, por isso mesmo o "problema de gênero" nos conduz a formularmos uma bioética.

Infelizmente a história não é linear e nem evolutiva como gostaríamos e o que vivemos hoje é um momento de grande retrocesso em relação ao que vivíamos há, pelo 
menos, uma década em termos sociais e de conquistas de direitos sexuais e reprodutivos. Vemos agora o aumento das estatísticas de violências de gênero e sexualidade - como feminicídio, assédio, estupro, LGBTQI+fobias - em parte, como decorrência dos discursos de ódio e da apologia às armas como solução para os conflitos cotidianos. Assistimos estarrecidos, e por vezes nos sentimos impotentes, porque pouco se consegue fazer em algumas circunstâncias diante de todas essas violências. ${ }^{5}$ Basta uma rápida entrada no site da Associação Nacional de Travestis e Transexuais (ANTRA) para nós apercebemos de que o momento requer nossa atenção e ação.

Em janeiro deste ano, mês da visibilidade trans, a ANTRA lançou um dossiê dos assassinatos e da violência contra pessoas trans brasileiras, referente ao ano de 2019 . Nesse dossiê, chama a atenção o fato de o Brasil continuar a ser o país que mais mata travestis e transexuais no mundo. O país passou de $55^{\circ}$ lugar de 2018 a $78^{\circ}$ lugar em 2019 no ranking de países mais seguros para a população LGBTQI+. Ou seja, no Brasil essas pessoas enfrentam cotidianamente o desprezo, a injúria, a rejeição e, nos termos tratados por Butler, em Problemas de Gênero, a abjeção - traduzida em conduta de alto grau de violência psíquica e física de desqualificação de sua condição humana.

A política de gênero oficialmente em curso na gestão bolsonarista das políticas públicas pode ser sumarizada como sendo uma incitação a fazer da abjeção uma norma não apenas naturalizada, como institucionalizada, apesar das (poucas) negociações e pressões jurídicas quanto aos seus abusos, visto que a criminalização pune os atos, ao menos aqueles denunciados e que deixaram marcas e registros. Porém, como sabemos, os pune individualmente (como exceção e não como sendo uma regra instituída

\footnotetext{
${ }^{5} \mathrm{O}$ próprio governo admite o aumento, mas opta por políticas públicas que visam atacar a violência de gênero pregando harmonia (conto de fadas), nas palavras da ministra: "sociedade de fraternidade e uma nação de respeito mútuo" Enquanto diz que vai atacar o problema, desmonta as estruturas de estudos e apoios que foram montadas ao longo de décadas e que ajudavam a monitorar o problema e a encontrar soluções. Uma leitura dos Dossiês publicados pelo IPEA, pelo Instituto Patricia Galvão, pelo observatório das Mulheres contra a violência do Senado, ajudam a dimensionar o tamanho do problema que coloca o país em $5^{\circ}$ lugar no ranking dos países que cometem mais homicídios contra mulheres. Nessa nota me refiro à notícia Balanço anual: Ligue 180 registra 1,3 milhão de ligações em 2019, Disponível em: $<$ https://www.gov.br/mdh/pt-br/assuntos/noticias/2020-2/maio/balanco-anual-ligue-180-registra-1-3milhao-de-ligacoes-em-2019>. Acesso em 10 de maio de 2021. Também me refiro à matéria Por que as taxas brasileiras são tão alarmantes? Publicada pelo site da Agência Patrícia Galvão. Disponível em: $<$ https://dossies.agenciapatriciagalvao.org.br/feminicidio/capitulos/qual-a-dimensao-do-problema-nobrasil/\#brasil-e-o-5o-no-ranking-de-homicidios-de-mulheres $>$. Acesso em 10 de maio de 2021.
} 
perversamente nas entranhas das instituições públicas como hospitais, escolas, famílias, e nos próprios atos públicos dos ministérios (em especial, da Mulher, Família e Direitos Humanos e o da Educação ${ }^{6}$ ). "A banalidade do mal”, expressão que foi formulada por Hannah Arendt em relação a contextos de extremo extermínio promovido pelo nazismo, pode, com a cautela necessária, ser pensada como ativa no contexto brasileiro. Isso porque a banalização da violência se faz na abjeção da alteridade, na negação daquilo que nos difere, no próprio ato de diferir, conformando uma sensibilidade política autoritária e violenta. ${ }^{7} \mathrm{O}$ pior de termos a abjeção como política é o fato de que isso faz com que uma nação se apoie em políticas públicas nefastas, em nome daquilo que consideram ser a sagrada família, o corpo natural biológico, a sexualidade verdadeira leia-se heterossexual - e os gêneros masculino e feminino, configurados no protótipo binário homem versus mulher - no singular - a partir de uma ontologia universal.

Nesse contexto, um texto como Problemas de Gênero ressoa como uma bomba destruidora. Por que o pensamento Butleriano - deixemos claro que ela não estava sozinha quando o formulou - incomodou e incomoda tanto? Arriscarei aqui algumas suposições em três campos distintos. O primeiro deles no próprio campo de estudos de

\footnotetext{
${ }^{6}$ Chamo atenção para todos os projetos voltados para o "fortalecimento da família". A título de exemplo, há o recente Projeto-Piloto Famílias Fortes que "consiste em uma metodologia de sete encontros semanais voltados para famílias com filhos entre 10 e 14 anos. O objetivo é promover o bem-estar dos integrantes da família com o fortalecimento dos processos de proteção e construção de resiliência familiar e a redução dos riscos relacionados a comportamentos problemáticos". Por todas as ações deste ministério, podemos supor que impor uma norma heteropatriarcal e uma noção nuclear e conservadora de família é a espinha dorsal do projeto, frontalmente um rechaço às existências que desafiam as normas hegemônicas de gênero. As informações podem ser encontradas na notícia Itapoá (SC) assina acordo para adesão ao programa Famílias Fortes publicada no site do Ministério da Mulher, da Família e dos Direitos Humanos. Disponível em: <https://www.gov.br/mdh/ptbr/assuntos/noticias/2021/abril/itapoa-sc-assina-acordo-para-adesao-ao-programa-familias-fortes>. Acesso em 10 de maio de 2021.

7 Faço um importante parênteses para ressaltar que essa tendência autoritária e desqualificadora das alteridades dissidentes perpassa as práticas de religiosos, profissionais da saúde (médicos em especial), profissionais da segurança e do judiciário há muitos anos e existe uma extensa bibliografia que a analisa. No entanto, paralelamente, há também uma crescente produção de material audiovisual que a denúncia. A título de exemplo, indico o documentário etnográfico de Debora Diniz, que expõe a intrincada microfísica deste poder de deixar morrer (ou de induzir à morte) pessoas vulneráveis devido a uma conjunção de fatores nas quais gênero, classe e a racialização dos corpos são protagonistas. No caso em tela, a correlação entre estupro/aborto de mulheres negras, sem acesso à moradia, educação, emprego, enfim, que vivem nos grupos mais marginalizados e precarizados do país. O título do documentário é $A$ Margem do Corpo (2006). Disponível em: <https://www.youtube.com/watch?v=4PoxtwM8nik>. Acesso em 18 de março de 2020. Indico ainda o filme Temporada de Caça (1988), de Rita Moreira (1988), Disponível em: <https://www.dailymotion.com/video/x2499gx>. Acesso 10 de maio de 2021.
} 
feministas e das ciências humanas, em relação ao entendimento a produção de conhecimento a respeito de como se produz e efetiva as identidades e relações de gênero, e as sexualidades normais e periféricas. Num segundo momento, falo um pouco sobre os movimentos sociais e a construção dos sujeitos de representação para reivindicação de políticas de direitos, formulações jurídicas, enfim, especificação de um campo de inteligibilidade dos grupos de pessoas que confrontam normas tanto de gênero quanto de sexualidade - isso porque sabemos que, voltando um pouco na história, não é só a direita conservadora que se opõe ao pensamento de Butler. Nós tivemos várias teóricas feministas importantes que tiveram grandes dificuldades com aquilo que a Butler estava propondo enquanto teoria política feminista, principalmente com a noção performativa de gênero e com o fato de que, embora feminista, sua visão não se baseia no sujeito mulher. O terceiro e mais óbvio ponto é o incômodo dos conservadores religiosos, mas não somente esses - também os políticos que estão agora no poder e em várias instituições brasileiras e aqueles inseridos também em práticas neoliberais que usam o Estado, os templos e a mídia como modo de agremiação e propagação de suas estratégias de perpetuação.

Percebam que, se hoje Butler é lida e apropriada em várias pesquisas no campo dos estudos feministas, estudos sobre mulheres e estudos de gênero dentro de diversas áreas conhecimento - que vão da educação física à psicologia, educação, artes visuais, história, antropologia, literatura etc. - isso não ocorreu sem conflitos, e, mesmo hoje, não é um consenso. Desde a primeira tradução de Fundamentos contingentes do feminismo e a questão do pós modernismo dentro de um livro organizado por Heloísa Buarque de Holanda em 1995 - texto que também foi traduzido em 1998 sob pelos cadernos PAGU - e, mais tarde, com a tradução dos Corpos que pesam, traduzido assim por Guacira Lopes Louro em 2001, a apropriação de suas ideias na academia brasileira passou por uma trajetória cheia de controvérsias. Demoramos mais de uma década para traduzir o Gender Trouble, em 2003. Depois, demoramos duas décadas para traduzir Bodies that Matter - Corpos que importam -, em 2015.

É preciso reconhecer que algumas leituras de seus trabalhos não lhe pouparam elogios, como é o caso do psicanalista Joel Birman, que, além de auxiliar coma revisão técnica da tradução, participa da sinopse da edição brasileira de 2003 de Problemas de 
Gênero, dizendo: "trata-se de uma obra ao mesmo tempo cortante e apaixonante. Com muita audácia, Butler coloca na berlinda os valores fundamentais de nossa tradição”. Carla Rodrigues, que resenhou o livro na época de sua publicação, traz também uma frase bombástica: "Dito de forma muito resumida, Problemas de gênero: feminismo e subversão da identidade desconstruiu o conceito de gênero no qual está baseada toda a teoria feminista". ${ }^{8}$ Hoje é possível afirmar que a receptividade das ideias da autora no território brasileiro cresceu e ainda cresce.

Mas vamos voltar ao livro. Li-o pela primeira vez, em 1993. Naquela época, recebíamos os livros de alguém que havia saído do país e o líamos utilizando a velha prática da cópia por xerox - pois não o encontraríamos na biblioteca da Unicamp. Acredito que o livro tenha sido trazido por Adriana Piscitelli ou por Marisa Corrêa e assim nós o incluímos em nosso grupo de estudos. Naquele momento, percebíamos que o ponto de vista teórico conceitual do livro promovia uma suspeição de várias verdades, autores e obras canônicas no âmbito das ciências humanas.

Butler tratava de Lacan, de Freud, de todo o debate que ocorre em relação ao luto e à melancolia de gênero, que para Butler produz (psiquicamente) a matriz heterossexual. Outra noção importante a ser contestada é a centralidade do falo nas teorias da psique, tanto por Freud quanto por Lacan. Neste livro, Butler faz uma crítica contundente às formas de problematização da subjetividade engendrada (marcadas pelas diferenças de gênero) trazida pela antropologia de Lévi-Strauss sobre parentesco e todo debate feito sobre a hipótese repressiva (já questionada por Foucault), que emoldura o arcabouço argumentativo de Freud, mas também opera em Lévi-Strauss quando em relação ao tabu do incesto se propõe a própria formulação da heterossexualidade numa matriz universal. Nem mesmo Foucault, autor que por sua elaboração da história da sexualidade e de suas noções de poder, exerce muita influência sobre Butler, ficou de fora de sua critica, uma vez que a autora também questiona em Foucault os resquícios de um pensamento estruturalista.

\footnotetext{
${ }^{8}$ RODRIGUES, Carla. Butler e a desconstrução do gênero. Rev. Estud. Fem., Florianópolis, v. 13, n. 1, p. 179-183, 2005.
} 
Perdoem essa "passada" superficial por campos importantes da fundação da psicanálise e da elaboração de uma antropologia e filosofia estruturalista. A intenção não é de aprofundar aqui o campo crítico elaborado, mas remeter ao choque ${ }^{9}$ que foi, na ocasião de uma primeira leitura, entrar em contato com Gender Trouble.

Butler trouxe ao fronte importantes autoras feministas, incluindo aquelas que realizavam uma importante reflexão a respeito do feminismo lésbico e a formulação da crítica à heterossexualidade compulsória. A autora também cita Simone de Beauvoir - e seu texto, clássico escrito na década de 1940, mas relido e devorado na década de 1960 e sua noção construcionista de gênero. Beauvoir dá um passo fundamental, reconhecido por Butler, mas que carrega consigo um limite. Ao afirmar a formação cultural do gênero, Beauvoir mantém intacta a diferença sexual como um ponto de partida, reforçando assim a estrutura binária sexo como um fato e o gênero como aquilo que é adquirido culturalmente. Aqui vemos uma distinção que permanecerá por muito tempo dentro do feminismo. Veremos muitos outros textos de Butler a continuar esse debate junto de algumas autoras feministas francesas.

Nas palavras de Butler (2003, p. 163): "Se o sexo não limita o gênero então talvez haja gêneros, maneiras de interpretar culturalmente o corpo sexuado que não estejam limitados pela aparente dualidade do sexo”. Assim, a autora começa a elaborar gênero como um devir histórico e não natural, incluindo o sexo como parte desse devir.

Outra feminista importante trazida ao debate por Butler é Monique Wittig que parte de S. de Beauvoir, ao historicizar a categoria mulher, mas questiona em Beauovoir o modo como o sexo aparece como uma categoria invariável, naturalizada. Para Butler, Wittig ajuda a pensar quando traz a categoria lésbica para desestabilizar o par sexo/gênero (natureza/cultura). Dessa forma, sexo e gênero não são categorias políticas descritivas estáveis. Vemos aqui que essa primeira leitura crítica de Beauvoir é

\footnotetext{
9 Escrevi uma primeira reflexão a partir deste primeiro encontro/leitura de G.T. na resenha de título Ainda temos muito o que dizer, publicada na Revista de Estudos Feministas em 1994. Mais tarde, em 1998, com a publicação de meu texto Posições de sujeito, atuações de gênero, na Revista de Estudos Feministas, voltei à Butler, mas já com Bodies that Matter em mente, puxando mais fios para pensar o trabalho da autora. Em ambos os textos, ainda não estava claro para mim que G.T. havia se tornado um ponto inaugural de uma "teoria queer". É interessante notar que, em Why Bodies Matter (2015), palestra em concedida em celebração dos 25 anos de sua obra fundamental, Butler comenta que, no início da década de 1990 e até mesmo na época da escrita de G.T., ela mesma não pensava em produzir as bases desse um marco teórico.
} 
apropriada por Butler que, por sua vez, elabora, ela mesma, um diálogo crítico com Wittig.

A autora destaca o fato de Wittig conceber o sexo como algo produzido discursivamente e difundido por um sistema de significações opressivo para as mulheres lésbicas. Não vislumbrando condições de subversão dentro dessa lógica discursiva, a autora francesa propõe uma linha radical de ruptura. Isso implica em produzir uma outra descrição dos corpos, sem diferenciação pronominal (ele/ela). No entanto, no entender de Butler (2003, p.167): "Na teoria de Wittig parece existir dois níveis de realidade, duas ordens de ontologia. A ontologia socialmente constituída emerge de outra, mais fundamental que parece ser pré-social e pré-discursiva”. Se, por um lado, Wittig avança em relação a Beauvoir ao trazer também o sexo para o campo da dimensão discursiva das relações de poder e de produção, por outro, ela mantém intacta a possibilidade de existir um elemento pré-discursivo e pré-social.

A tarefa prática que as mulheres enfrentam ao tentarem criar a subjetividade por meio da fala depende de sua capacidade coletiva de descartar as reificações do sexo a elas impostas, e que as deformam como seres parciais ou relativos.

Butler (2003, p. 170) elogia no pensamento de Wittig e seu esforço para dar conta da potência contida nos desafios práticos enfrentados pelas mulheres ao produzirem subjetividade por meio da fala. Isso, por sua vez, depende da capacidade coletiva de descartar as reificações do sexo a elas impostas e que as deformam como seres parciais ou relativos, frente à concepção de os homens estariam sempre na esfera do universal e as mulheres na esfera do particular. Já a crítica de Butler a Wittig poderia ser resumida dessa forma: ainda que a autora francesa critique a universalização e centralização do ponto de vista heterossexual, ela mesma parece não só universalizar a própria mentalidade hétero, ${ }^{10}$ como também desconsiderar as consequências totalitárias dessa teoria dos atos soberanos de fala (BUTLER, 2003, p. 171). Butler alude às armadilhas das identidades que se voltam o tempo todo contra críticas, que se consideram uma verdade

\footnotetext{
${ }^{10}$ Como também faz Bourdieu em A Dominaçāo masculina. Conf. a maravilhosa crítica de Mariza Corrêa ao textos de Bourdieu em: CORREIA, M. O Sexo da Dominaçāo. Novos Estudos, n. 54. 1999.
} 
absoluta. Insiste na necessidade de estarmos sempre atentas a essa vocação totalitária de algumas teorias e seus efeitos políticos.

A relação de sujeição não é única, portanto, há diferentes distinções nos modos de ser hétero, homo, trans e não-binário, que nos impedem de fazer suposições e/ou oposições simplistas. Não basta ocupar a posição de um sujeito falante, como na sugestão de Wittig, e fazer deste ponto particular um ponto de vista universal. Ao retomar o universal sob a perspectiva de um "nós”, que não mais é hétero, continua-se se estabelecendo uma contraposição entre lésbicas e héteros. Ainda que afirme inverter a posição do sujeito, Wittig deixa intocada a vocação da existência de uma estrutura universal que ancora um todo.

Hoje poderíamos evocar na crítica de Butler a Wittig aquilo que as feministas decoloniais latino-americanas vêm problematizando na crítica ao eurocentrismo. No livro que Butler organizou com Joan Scott em 1992, ${ }^{11}$ sobre pós-modernismo e política, Butler já se refere às teorias pós-coloniais - assim as chamávamos, na época. Essas teorias estavam justamente questionando o eurocentrismo do pensamento feminista, trazendo para o debate a questão das mulheres negras, lésbicas e trans nos trópicos. Podemos aproveitar essa crítica e problematizar as diferenças entre ser e lésbica e trans na Europa e fora dela - essas diferenças trazem outras questões políticas fundamentais para pensarmos as formulações ontológicas que possibilitam discursos de reivindicação de legitimidade diante de opressões, mas que também reinstauram universalidades. Por vezes, temos a boa intenção de criar uma posição de sujeitos com uma fala potente, mas essa fala potente universaliza e silencia todo um conjunto de possibilidades de ação conjunta.

Nesse sentido, entendo que há no pensamento de Butler, tanto em Gender Trouble, quanto em Bodies That Matter, uma crítica radical ao universal e uma aposta político-teórica na potência do pensamento voltado a uma lógica das contingências e das alianças, traduzidas como coalizões. No contexto brasileiro, Berenice Bento expandirá as pesquisas nessa temática. Sugiro a leitura de seus últimos livros, principalmente Sexualidade, Gênero e Violência: um estudo sociológico (2019). Também

11 SCOTT, J. W.; BUTLER, J. Feminists theorize the political. New York: Routledge. 1992. 
sugiro a leitura de $O$ desejo da nação: masculinidade e branquitude no Brasil no século XIX (2012), de Richard Miskolci onde, a partir da leitura de textos literários, o autor traz um pouco desse entrecruzamento entre questões de raça, gênero e a produção de um ideal de nação, expandindo o debate em torno da crítica radical ao universal a fim de mostrar na política do embranquecimento e no projeto moralizante as entranhas da biopolitica brasileira como cerne do projeto de "nação".

Voltemos ao ponto de partida a partir do qual Butler indaga: como operam os discursos sobre o gênero? A partir dessa questão, ela nos convoca a pensar sexo, gênero e desejo como efeitos de uma formação específica de poder. Portanto, supõe uma forma de investigação crítica à qual Foucault, lendo Nietzsche, deu o nome de genealogia. Assim, já de início ela traz a ideia de que não é possível formular o par sexo/gênero, um sendo ligado ao fato natureza e o outro ligado à cultura, às agências, à história. No lugar do par (sexo/gênero) ela propõe uma tríade - sexo, gênero e desejo. O feminino e a feminilidade não são noções estáveis do ponto de vista sócio-histórico e não estão numa relação de causa/efeito com os corpos. Isso será realmente importante para a reformulação do feminismo. Sei que houve um revival da noção de patriarcado dentro dessa nova primavera feminista, trazendo-a à baila para nomear as estruturas de poder que constituem as desigualdades entre homens e mulheres nas sociedades ocidentais. A categoria foi muito utilizada numa perspectiva marxista de feminismo, e remete a uma compreensão específica do funcionamento das relações de poder que coloca importantes críticas ao liberalismo e à modernidade. Mas é importante lembrar que, em 1990, na produção do livro, Butler está em contato com várias importantes críticas ao caráter unilateral e universal dessa categoria, cujo uso cria um antagonismo entre homens e mulheres. Não é possível deduzir dai que não ocorram violências, opressões e desigualdades (institucionalizadas e do ponto de vista social e individual) de homens sobre mulheres. Contudo, a discussão aqui trata da sistematicidade e no modo pelo qual essa relação de poder está sendo colocada.

Em Gender Trouble, é possível perceber que as discussões que a autora realiza quando se refere ao funcionamento das relações de poder está mais focada na crítica ao falocentrismo, pois essa noção traz outros elementos simbólicos e permeáveis que permitem dar às relações hierárquicas desiguais entre os gêneros uma dinâmica menos 
centrada na identidade e mais focada nas práticas de produção de corpos gendrados, generificados - palavras usadas para traduzir engendered. O modo como Butler articula a performatividade de gênero, a crítica ao falocentrismo e à heterossexualidade compulsória, cria, a meu ver, essa tríade teórica que a auxiliam a pensar a dinâmica de relações de submissão e subversão das normas e convenções de gênero para além do modo como a categoria patriarcado faz. É claro que despatriarcalizar é uma necessidade, mas é interessante observar como, do ponto de vista conceitual, a aproximação com a noção foucaultiana de poder permite à autora problematizar as subversões e a luta direta contra o neoliberalismo e o falocentrismo para além da centralidade da luta de classes e da luta contra o Estado. Todas essas reformulações jurídicas para um Estado mais inclusivo também têm espaço no pensamento de Butler, mas está presente de uma maneira em que a autora questiona se a única forma de subversão será sempre apenas por esse tipo de produção de um sujeito de representação, de um sujeito que demanda inteligibilidade via o Estado.

Sua aproximação a uma perspectiva pós-estruturalista - portanto, ligada a uma dimensão microfísica de poder, a uma noção de genealogia das análises dos discursos propõe certos cuidados quando a juntamos com perspectivas feministas mais assentadas em modos marxistas, mais estruturados em macro dimensões do poder que operam com essa noção de sujeito e resistência de maneira distinta àquela com a qual Butler trabalha. Categorias de identidade são, na verdade efeitos, de instituições práticas e de discursos cujos pontos de origem são múltiplos e difusos. ${ }^{12}$ Por conta dessa linha de raciocínio, a autora foi acusada de despolitizar o feminismo, uma vez que sua perspectiva trazia instabilidade para a categoria mulher, até então base e fundamento para as políticas feministas e da luta contra o patriarcado. Nesse sentido, gênero não é uma identidade estável ou um lócus de agência a partir do qual vários outros atos decorreriam. Ao contrário, é uma identidade tenuemente constituída no tempo através de uma processual repetição estilizada de atos. ${ }^{13}$

\footnotetext{
12 BUTLER, Judith. Problemas de gênero: feminismo e subversão da identidade. Rio de Janeiro: Civilização Brasileira, 2013, p. 9.

13 Ibidem, p. 200.
} 
Apesar de tamanho passo em direção a uma compreensão desnaturalizada e dessencializada da noção de mulher, tanto a formulação de Beauvoir quanto a noção de patriarcado partem de uma distinção sexo/gênero que recompõem uma clássica visão dual filosófica/antropológica entre natureza/cultura, indivíduo/sociedade, corpo físico/corpo psíquico etc. A aposta butleriana no caráter performativo dos gêneros e na maneira como isso lhe permitiria pensar as praticas de subversões de gênero em ações paródicas sem efeitos estruturantes ou políticos, fez com que a autora fosse também muito apreciada por movimentos artísticos e culturais no universo camp, drag e transformista, no âmbito do teatro, das artes visuais, no audiovisual e na literatura, pois ajudou a formular o entendimento de que essas práticas desnaturalizam e são disruptivas dos processos de normatização do binarismo de gênero e da heteronormatividade. Porém, no afã de entendermos o fluido em contraposição ao fixo, a própria noção de devir do gênero foi muito banalizada nesses últimos anos e traduzida numa interpretação construcionista que está longe daquilo que Butler tentou formular em Gender Trouble e Bodies that Metter.

É claro que nada se compara à deliberada deturpação que foi feita por pessoas como nossa ministra da Mulher, da Família e dos Direitos Humanos, Damares Alves, que, ao formular como "ideologia de gênero" as pautas por educação sexual e de gênero que tentavam trabalhar as LGBTfobias no âmbito escolar e social, diz no seu primeiro discurso de posse, que o Brasil está numa nova era e meninos vestem azul e meninas vestem rosa. ${ }^{14}$ Esse gesto inaugural de governo sintetizou toda uma reação direta e grotesca à compreensão performativa de gênero. Ao longo desses dois anos a ministra proferiu várias piadas em suas diversas falas, retomando o caráter fixo e imutável do par sexo/gênero, em contraposição ao que ela entende como uma imposição esquerdista de valores sobre o sexo e sobre o ser mulher ou homem. A palavra gênero é desconsiderada no vocabulário da ministra. Uma das piadas diz assim: “Ah, você já ouviu falar que você dorme mulher e amanhece homem?" - num esforço de banalização das transformações corporais e subjetivas de pessoas dissidentes do binarismo. De qualquer forma, não me

\footnotetext{
14 'Menino veste azul e menina veste rosa', diz Damares Aves. Portal Estado de São Paulo, Disponível em: $<$ https://wwwi.folha.uol.com.br/poder/2019/o1/menino-veste-azul-e-menina-veste-rosa-dizdamares.shtml>. Acesso em 10 de maio de 2021.
} 
estenderei na análise dos usos estratégicos de fake news, memes e outros recursos antiéticos e publicitários para dar visibilidade a esse projeto conservador-moralizante de dominação simbólica. A respeito do tema, existem várias reflexões sérias publicadas. Como exemplo, indico um dossiê nos Cadernos Pagu organizado por Richard Miskolci e Pedro Paulo Pereira, intitulado Quem tem medo de Judith Butler? A cruzada moral contra os direitos humanos no Brasil (2018). Ali estão contidos textos muito instigantes e que ampliam muito o tema sobre o qual estou tratando agora. Indico outro texto do próprio Miskolci, ${ }^{15}$ no qual ele empreende uma importante genealogia e uma reflexão bem detalhada sobre o que é essa cruzada moral do bolsonarismo - a verdadeira dimensão política dessa cruzada moral.

Bom, assim como esse bolsonarismo perseguiu Butler, também perseguiu Paulo Freire, Gramsci, Beauvoir - Butler e Beauvoir justamente por acenarem ao fato de que a anatomia não é um destino, portanto, ser mulher não é algo natural.

Como já mencionado anteriormente, Michael Foucault e Monique Wittig, autores que propuseram leituras radicais do tema ao afirmarem a própria instabilidade do corpo e do sexo, permitiram com que Butler pudesse, a partir daí, elaborar um pouco melhor sua própria compreensão da materialidade do gênero e do corpo - pensando este segundo como uma linguagem permeada por efeitos de poder. Assim, a autora estadunidense elaborou um de seus principais argumentos, além do caráter performativo do gênero: a não necessária contiguidade, linearidade ou relação causal entre sexo, gênero e desejo. Na minha leitura, esse é um dos principais pontos de Gender Trouble. Essa formulação desemboca numa crítica importante à política de representação jurídica fundada em identidades reificadas e, por ser crítica da política identitária, passou a ser nomeada e reconhecida por teoria queer, algo que a própria autora explica ${ }^{16}$ que veio em decorrência das apropriações do livro, juntamente às outras obras que foram escritas no mesmo período e não como uma proposição deliberada dele.

\footnotetext{
${ }^{15}$ MISKOLCI, R. Exorcizando um fantasma: os interesses por trás do combate à "ideologia de gênero". Cadernos Pagu, $\quad$ n. 2018. 53, Disponível em: $<$ https://periodicos.sbu.unicamp.br/ojs/index.php/cadpagu/article/view/8653409>. Acessado em 10 de maio de 2021.

${ }^{16}$ Aqui me refiro novamente à Why Bodies Matter, palestra mencionada acima, na qual a autora comenta a repercussao do livro, mencionando justamente esse fato: "[...] I am in fact the author of that book (G.T.), but I have changed in the last course of 25 years, and the book has taken a life on its own (...). It
} 
Butler se protege das possíveis críticas, afirmando que "A desconstrução da identidade não é a desconstrução da política; ao invés disso, ela estabelece como políticos os próprios termos pelos quais a identidade é articulada" ${ }^{17} \mathrm{Se}$, no primeiro capítulo, a autora dialoga diretamente com a tradição feminista de pensamento vigente até aquele momento, na seção seguinte ela se dedica a analisar as práticas de saber e conhecimento sobre a sexualidade, tendo a psicanálise no centro desse debate. Butler analisa a relação entre a proibição do incesto e a produção da matriz heterossexual. ${ }^{18}$

Nunca é demais lembrar que Butler estava inserida em um momento do pensamento feminista em que ela e outras pensadoras, como Gayle Rubin, por exemplo, se debruçavam sobre o conhecimento sexual, relendo sexólogos do século XIX e início do século XX - analisando como se deu alí a construção das patologias e as normalidades no entendimento do corpo e da sexualidade. Refiro-me a nomes como Richard von Krafft-Ebing, Magnus Hirschfeld e Havelock Ellis, que, nesse período histórico, discutiam as teorias do instinto sexual, da homossexualidade como inversão - teríamos aqui Hirschfeld como, talvez, um dos primeiros ativistas médicos e teóricos que objetivava despatologizar a questão homo e trans, concebendo-as como parte de uma normalidade, ainda pouco conhecida dos discursos que vinham sendo construídos durante o século XIX.

Em Corpos que Importam (2018) a autora retoma ambas as noções de performatividade de gênero e de materialidade do sexo para esclarecer o que a distância tanto de um projeto filosófico humanista quanto do construcionismo cultural, que dão ênfase às escolhas de um sujeito considerado pré-existente ou desconsideram as circunstâncias constritas nas quais os corpos são materializados e sexuados. Em outras palavras, interessa a Butler entender a construção cultural dos corpos, mas não como algo desencarnado ou como se o corpo fosse pura abstração. Pelo contrário, preocupase com o fato de que os mesmos mecanismos que produzem inteligibilidade cultural de

\footnotetext{
was written in the same time as many others important books that helped to instigates queer theory at that time, that wasn't my intention, was surprised by the outcome”. (BUTLER, 2015).

17 BUTLER, Judith. Problemas..., p. 213.

${ }_{18}$ Para um maior aprofundamento entre psicanalise e o pensamento de J. Butler, sugiro a leitura do texto de ARÁN, M.; PEIXOTO JÚNIOR, C. A. Subversões do desejo: sobre gênero e subjetividade em Judith Butler. Cadernos Pagu, n. 28, jan.-jun., 2007, p. 129-147.
} 
certos corpos produzem também aqueles considerados impensáveis, abjetos, sem direito à vida. Ou seja, trata-se de uma construção conjunta, que se dá a partir de uma relação.

Apesar de gastar em detalhamento e exposição para elaborar esse argumento, Butler dedica-se igualmente a ilustrar, enfatizar e abrir espaço para as arejadas práticas de subversão dessas rígidas e constritivas normas que regulam as práticas demarcadas pela dinâmica performativa do gênero, sexualidade e desejo. Eu destacaria dois tópicos tratados, tanto em Bodies that matter quanto em Undoing Gender, que ilustram o tom polêmico de suas reflexões sobre atos subversivos. Um deles é a crítica a ideia de que o falo lésbico seria apenas um reiterador da dominação simbólica masculina. Butler se opõe a essa ideia. Afinal, o que uma mulher com trejeitos (gestos, vestuário, estilo de corte de cabelo, maneirismos no vocabulário etc.) lidos a partir do repertório do "machāo", o que na linguagem popular se denomina lésbica "caminhoneira", teria de subversiva se a sua performance fosse apenas uma ação mimética de uma masculinidade fálica da qual muitos homens estão querendo se livrar? A autora responde que não se trata contemporizar a dominação simbólica masculina, mas de compreender que o simples fato de se deslocar a masculinidade do corpo entendido como masculino por sua natureza e localizá-la em novas corporalidades - ou seja, desgrudar o par masculinofeminino das identidades homem-mulher - abala as noções do que entendemos por corpo humano e por diferença sexual. Nas palavras de Butler, "o falo lésbico oferece então ocasião para que o falo, como essa imagem simbólica, signifique diferentemente e, assim, significando outra coisa, traga a possibilidade de ressignificar seu privilégio masculinista e heterossexista”. ${ }^{19}$ Tal reflexão sobre os modos de ressignificação do simbolismo do falo amplia enormemente a compreensão política dos processos de transexualização masculina, não necessariamente ligadas às práticas lésbicas e muito menos ao falocentrismo.

Afinal, ainda temos algumas feministas, que se ligam historicamente ao importante legado das radicais das décadas de 6o e 70 (RadFem), com dificuldades de

\footnotetext{
${ }^{19}$ Traduçāo livre do trecho: "the lesbian phallus offers the occasion (a set of occasions) for the phallus to signify differently, and in so signifying, to resignify, unwittingly, its own masculinist and heterosexist privilege", retirado de BUTLER, Judith. Bodies that matter: on the discursive limits of "sex". New York: Routledge, 2011, p. 106.
} 
entender porque uma mulher "se transformaria em um homem e ainda assim seria feminista" - esse é o entendimento limitado que elas têm de um homem trans. Esta aparente contradição fez com que durante muito tempo a transexualidade fosse vista como um retrocesso, um conservadorismo político-filosófico, porque justamente traria para o âmbito do feminismo "homens" que querem tomar para si o "ser" mulher, mas oriundos e imersos nas violências patriarcais praticadas historicamente contra as mulheres. Isso porque parte dos argumentos que sustentam a transexualidade se pautam pela tentativa de correção da unidade sexo-gênero. Ao contrário destas oposições binarias no entendimento da transexualidade e das diferenças sexuais, na leitura de Butler, é importante, ao mesmo tempo, deslocar o feminismo de um ideal puro do feminino, implodir a dicotomia homem/mulher e estar consciente de que qualquer reinvenção de nós mesmos, em termos de gênero e sexualidade, não se dá à parte ou tampouco fora dos campos normativos e das regras de inteligibilidade constituídas historicamente. Em outras palavras, não cabe atribuir às pessoas transsexuais a retomada de um gênero normativo. Não há como nos livrarmos do simbolismo do falo, senão pela reiteração e, nela, a ressignificação que traz um possível deslocamento dos privilégios atribuídos ao mesmo.

Recentemente, os estudos de Butler enveredaram por questões políticas, consideradas mais amplas, que questionam as relações entre poder bélico-jurídico e o exercício estatal da violência. Em especial, nas suas contundentes análises do conflito Palestina-Israel. Posicionando-se como judia ao mesmo tempo crítica das posturas e ações da atual política israelense, Butler estendeu os argumentos sobre a precariedade e vulnerabilidade de certa corporalidade queer - os assassinatos e a discriminação das travestis e dos corpos que não importam na atual matriz de inteligibilidade - para problematizar o tratamento desumanizador de civis palestinos nos abrigos. Butler levanta diversas questões: para quem e em quais circunstâncias a cidadania, enquanto direito, é concedida dentro dessas zonas de conflito armado? Como importam os corpos dos soldados, das crianças, das mulheres, dos sem-teto, sem Estado, sem nacionalidade?

Para alguns, as discussões butlerianas sobre moral, humanismo, poder e sua contundente crítica ao neoliberalismo político-filosófico representaria uma guinada, uma mudança de foco de suas reflexões sobre gênero e sexualidade. Reconheço, com 
uma certa tristeza, que Butler só conquistou a legitimidade e o status de um pensamento sério quando o reconhecimento sobre sua trajetória de estudos se deu não apenas por sua longa inserção no campo dos estudos feministas, de gênero e de sexualidade, mas quando retomou esses elementos de um outro modo e ampliou o debate para pensar a precariedade dos corpos, não só dos que importam na codificação do legível e reconhecível em termos de gênero, mas sobretudo dos corpos em sua vulnerabilidade e exposição nos territórios envolvidos em conflitos armados. Conflitos éticos de teor político-econômico esbarram não apenas nas diferenças em termos de gênero e sexualidade, mas sobretudo nas categorias dominantes de pertencimentos étnicos, religiosos e nacionalistas. No entanto, Butler tem sido firme, em entrevistas e textos, ao afirmar que na verdade é sua postura feminista e queer que a compele a pensar nesses processos de racialização e a multiplicidade dos dispositivos e mecanismos de poder que forçam historicamente a construção de uma barreira entre humano e não-humano, entre corpos hegemônicos e corpos precarizados.

À guisa de uma conclusão, me foco sobre a apreensão de Butler dentro dos movimentos sociais no Brasil, e sobre como autora é inserida dentro do que chamamos de cultura pop - que abrange personagens de telenovela e reality shows, mas também peças dirigidas por Zé Celso, paradas do orgulho gay e toda essa onda de uma nova visibilidade de transexuais, travestis e de corpos queer na cena brasileira nos últimos 20 anos.

Toda essa movimentação ampliou o poder de inserção e visibilidade de subjetividades consideradas desviantes na grande mídia, para além da reiteração de sua presença nos espaços marginais ou paralelos já antes conquistados. Há ampla ramificação das vias de acesso a um mundo antes restrito apenas a alguns grupelhos. Ao mesmo tempo, vigora neste momento político brasileiro a presença também massiva e preocupante de políticos e grupos religiosos fundamentalistas. Nos últimos 20 anos houve, concomitantemente, um grande investimento na visibilidade das demandas desse corpo queer e um, a seu contraponto político, boom de grupos religiosos fundamentalistas destilando atos de violência política verbal e não verbal. Vimos nos últimos três ou quatro anos uma crescente pressão para que as instituições suprimam as iniciativas nas quais nos empenhamos para ampliar a sensibilização em relação a essas 
políticas de entendimento do que são esses corpos queer enquanto parte da sociedade como um todo. Nesse sentido, se antes Butler partia de leituras direcionadas apenas para um grupelho acadêmico, hoje o seu alcance é muito mais reluzente. Pelos motivos acima discutidos, torna-se também necessário, que retomemos aqui e acolá essas leituras e as questões instigantes colocadas pela autora.

Para finalizar essa reflexão, deixo uma pergunta para vocês e para mim mesma: conseguimos pensar nossas práticas a partir dessa radicalidade proposta e sugerida pelas reflexões de Butler há 30 anos atrás? Conseguimos pensar políticas que transcendam a luta por direitos que supõem sujeitos de direito marcados por identidades fixas de gênero, classe, raça e sexualidade? Estamos preparados para as políticas de aliança às quais Butler tanto nos convoca?

Obrigada pelo convite e pela atenção!

\section{Referências}

ARÁN, Márcia; PEIXOTO JÚNIOR, Carlos Augusto. Subversões do desejo: sobre gênero e subjetividade em Judith Butler. Cadernos Pagu, n. 28, jan.-jun., 2007, p. 129-147.

BALANÇO anual: Ligue 180 registra 1,3 milhão de ligações em 2019, Ministério da Mulher, da Família e dos Direitos Humanos, 2020. Disponível em: <https://www.gov.br/mdh/pt-br/assuntos/noticias/2020-2/maio/balanco-anual-ligue180-registra-1-3-milhao-de-ligacoes-em-2019>. Acesso em 10 de maio de 2021.

BESSA, Karla Adriana Martins. Ainda temos muito o que dizer, Revista Estudos Feministas, 1994.

BESSA, Karla Adriana Martins. Posições de Sujeito, Atuações de Gênero. Estudos Feministas, p. 34-45, 1998.

BUARQUE, Chico. Geni e o Zeppelin. In: Opera do Malandro, 1978 (álbum musical).

BUTLER, Judith. Não é o fim da história', diz filósofa sobre ensino de gênero nas escolas. G1, 2015. Disponível em <http://g1.globo.com/educacao/noticia/2015/og/nao-e-o-fimda-historia-diz-filosofa-sobre-ensino-de-genero-nas-escolas.html>. Acesso em 10 de Maio de 2021. 
BUTLER, Judith. Problemas de gênero: feminismo e subversão da identidade. Rio de Janeiro: Civilização Brasileira, 2013.

BUTLER, Judith. Bodies that matter: on the discursive limits of "sex". New York: Routledge, 2011.

CORREIA, M. O Sexo da Dominaçāo, Novos Estudos, n. 54. 1999.

ITAPOÁ (SC) assina acordo para adesão ao programa Famílias Fortes, Ministério da Mulher, da Família e dos Direitos Humanos, 2021. Disponível em: <https://www.gov.br/mdh/pt-br/assuntos/noticias/2021/abril/itapoa-sc-assina-acordopara-adesao-ao-programa-familias-fortes $>$. Acesso em 10 de maio de 2021.

'MENINO veste azul e menina veste rosa', diz Damares Aves. Portal Estado de São Paulo, 2019. Disponível em: <https://www1.folha.uol.com.br/poder/2019/o1/meninoveste-azul-e-menina-veste-rosa-diz-damares.shtml>. Acesso em 10 de maio de 2021.

MISKOLCI, R. Exorcizando um fantasma: os interesses por trás do combate à “ideologia de gênero". Cadernos Pagu, n. 53, 2018. Disponível em: <https://periodicos.sbu.unicamp.br/ojs/index.php/cadpagu/article/view/8653409>. Acessado em 10 de maio de 2021.

POR QUE as taxas brasileiras são tão alarmantes?, Agência Patrícia Galvão. Disponível em: $\quad<$ https://dossies.agenciapatriciagalvao.org.br/feminicidio/capitulos/qual-adimensao-do-problema-no-brasil/\#brasil-e-o-5o-no-ranking-de-homicidios-demulheres $>$. Acesso em 10 de maio de 2021.

RODRIGUES, Carla. Butler e a desconstrução do gênero. Rev. Estud. Fem., Florianópolis, v. 13, n. 1, p. 179-183, 2005.

SCOTT, J. W.; BUTLER, J. Feminists theorize the political. New York: Routledge. 1992. 